\title{
Polymorphism for disease resistance in the annual legume Amphicarpaea bracteata
}

\author{
Matthew A. Parker
}

Department of Biological Sciences, State University of New York, Binghamton, New York 13901, U.S.A.

Amphicarpaea bracteata plants from a single population varied greatly in disease resistance when inoculated with six different strains of the specialist pathogen Synchytrium decipiens collected from the same site. Selfed progenies of two plants exhibited heterogeneity in disease resistance. Inoculation experiments indicated that variation in disease resistance in these plant families was controlled by a single locus, with resistance exhibiting nearly complete dominance. This resistance factor was effective against only a limited number of the pathogen genotypes present in this area. Thus, its selective value will depend on the genetic structure of the pathogen population, which may result in frequency-dependent fitness variation for this trait.

\section{INTRODUCTION}

Recent studies of plant-pathogen interactions in natural communities have revealed that variation in plant disease resistance is widespread (Wahl, 1970; Zimmer and Rehder, 1976; Burdon, 1980; Segal et al., 1980; Burdon and Marshall, 1981; Burdon et al., 1983; Alexander et al., 1984; Dinoor and Eshed, 1984; Parker, 1985; Harry and Clarke, 1986). This extensive variability implies that natural plant populations have the capacity to undergo significant adaptive evolution in response to pathogen attack. However, most existing studies of natural plant-pathogen interactions have not examined the inheritance of observed phenotypic variation in disease resistance. Thus, the genetic basis for evolutionary change in this trait within natural plant populations remains poorly understood. Furthermore, many studies have yielded little information about the actual structure of plant-pathogen interactions in natural environments, since plants have been tested with arbitrary pathogen genotypes not necessarily representative of those found in their native habitats (Dinoor and Eshed, 1984).

In this study, variation in disease resistance in Amphicarpaea bracteata (Leguminosae), an annual plant that occurs in woodland habitats throughout eastern North America, is examined. $A$. bracteata is attacked by a host-specific fungal pathogen, Synchytrium decipiens (Chytridiomycota), which can have a major impact on the lifetime reproductive success of plants (Parker, 1986). Previous studies of $A$. bracteata have documented significant between-population differences in plant disease resistance toward particular pathogens. A. bracteata plants are typically highly susceptible to pathogens from their native location, and resistant to pathogens from other sites (Parker, 1985). Reported on here are patterns of variation in disease resistance and pathogen virulence within a single population of $A$. bracteata, examining the following questions. First, how specific is plant resistance? Is resistance limited to certain pathogen genotypes, or is it broadly effective against the entire pathogen population? Second, what is the genetic basis of observed variation in plant disease resistance?

\section{STUDY ORGANISMS}

A. bracteata is an annual vine with a mixed breeding system, producing both obligately selfpollinated cleistogamous flowers and potentially outcrossed chasmogamous flowers. Due to the low frequency of chasmogamous seed production (typically $<10$ per cent and often $\ll 1$ per cent), most $A$. bracteata populations are highly inbred (Parker, 1986; Schnee and Waller, 1986). S. decipiens is a strictly asexual pathogen (Karling, 
1964) that forms bright orange sori on the leaves, stems and fruits of its host. Heavy infection may result in plant growth deformities (Parker, 1986) or even death. Each sorus is formed when a single fungal zoospore penetrates a single host cell. The entire life cycle is completed in 17-28 days.

\section{MATERIALS AND METHODS}

Plants and pathogens were sampled from a single Illinois population, the LD site, which has been described previously (Parker, 1985, 1986). In October 1983, chasmogamous seeds were collected from 9 individual plants growing at least 1 metre apart from one another in this population. From each parent, one seed was selected at random, grown to maturity, and its selfed progeny were collected. Each of these selfed progeny groups, subsequently termed families, was inoculated with six different pathogen strains obtained from the same population in 1984 . The pathogen strains were collected from three sites $6 \mathrm{~m}$ apart along a transect, denoted A, B, and C. Each strain was derived from a mass collection of spores from a single infected plant in the field. For these initial tests, I did not attempt to establish strains that were genetically uniform. Instead, each strain represented the level of pathogen genotypic diversity that a plant might encounter at any one time in nature.

The inoculation procedure (described in Parker, 1985; 1986), involved simultaneous immersion of seedlings from different families in an aqueous suspension of fungal zoospores for 12 hours. A mean of 19 seedlings (range, 9-25) was inoculated for each of the 54 plant family/pathogen strain combinations (1022 total seedlings). Seedlings were then planted in a greenhouse, and fungal infection success was scored after 25 days. For each plant family/fungal strain combination, 200 fungal sori were examined (40 per leaf on each of 5 seedlings) and classified into one of two states: (a) Healthy-the sorus was large and full of orange sporangia, or (b) Aborted-the sorus had turned black and shrunk without producing any spores. The average percentage of sori aborting per plant family was used as an index of its disease resistance for each pathogen strain.

\section{RESULTS}

Each of the six pathogen strains successfully initiated sorus development on all nine plant families tested. Fungal sorus abortion rates were less than 5 per cent in 43 out of 54 plant family/pathogen strain combinations (fig. 1). Thus, most plants were strongly susceptible to most of the pathogen strains. In two of the plant families, a high frequency of pathogen developmental failure occurred with some of the pathogen strains. Resistance in these two families was strongly differential with respect to fungal strain (Kruskal-Wallis ANOVA, $H=26.7$ and 31.0 for families 3 and 4 respectively, $5 \mathrm{df}, p<0.001$ for both families). Despite resistance to certain strains, these two families were as susceptible as the other plants to the two pathogen strains collected from Site A. Thus, these results indicate that genetic variation is found not only among plants, but exists within the pathogen population as well.

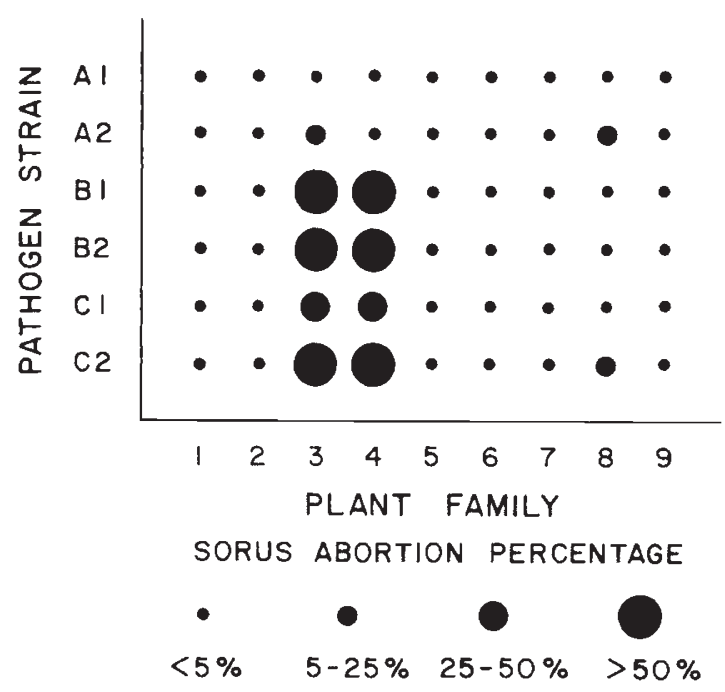

Figure 1 Sorus abortion frequency for 9 A. bracteata families inoculated with 6 different strains of $S$. decipiens. Data are the mean percentage of fungal sori aborting for each plant family/pathogen strain combination.

Within the two families exhibiting partial resistance, the abortion rate of fungal sori differed widely among sibling plants (fig. 2). On the majority of seedlings in both families, the frequency of sorus abortion was very high. However, pathogens developed quite successfully (abortion rate $<5$ per cent) on $5 / 25$ plants in family 3 and $3 / 15$ plants in family 4 . This heterogeneity in disease reaction phenotype suggested that segregation for disease resistance was occurring in these families.

To examine this hypothesis, selfed progeny were obtained from several individual plants (subsequently termed lines) representing both the high and low sorus abortion phenotypes of fig. 2. These progeny were inoculated with a genetically uniform isolate from one of the Site B pathogen strains. The isolate was established with spores collected from a single sorus. Sorus abortion 


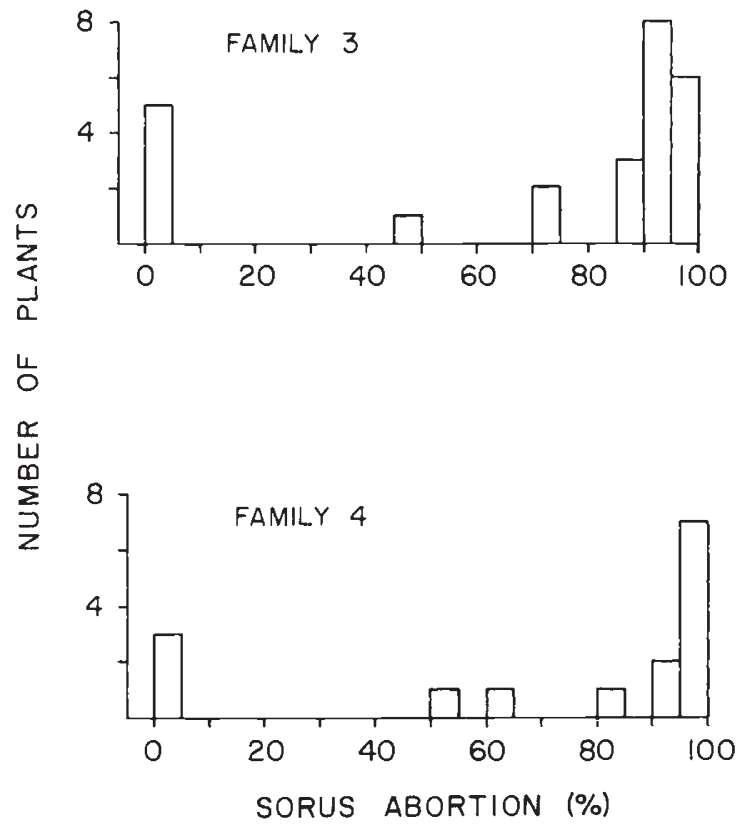

Figure 2 Variation in sorus abortion frequency among individual plants in two $A$. bracteata families inoculated with one strain of $S$. decipiens from Site $B$. frequency was quantitatively measured on 499 progeny plants, with a mean of 220 sori scored per plant. Sorus abortion rates fell into two discrete phenotype classes: 84 per cent of the plants $(421 / 499)$ had a sorus abortion rate of $<10$ per cent or $>90$ per cent. In further inoculation tests involving 239 plants, sorus abortion was censused only qualitatively, with each plant classified in one of two disease reaction categories: (a) resistantabortion frequency of fungal sori $>50$ per cent, or (b) susceptible-sorus abortion frequency $<50$ per cent.

The data of fig. 2 suggest that the trait of resistance is dominant over susceptibility. Therefore, susceptible individuals, being homozygous recessive, should breed true for susceptibility. This prediction was confirmed (table 1 ). All progeny of susceptible plants within both families were susceptible, with a mean sorus abortion frequency of about 5 per cent.

A further prediction under the hypothesis of single locus inheritance is that resistant plants of fig. 2 should be a mixture of heterozygotes and homozygotes. Segregation should thus occur in the selfed progeny of some, but not all, of these plants.

Table 1 Disease reaction phenotypes among selfed progeny of susceptible and resistant individuals in two $A$. bracteata families inoculated with an isolate of $S$. decipiens. For segregating lines, chi-square test statistic for fit to $3: 1$ ratio is given in last column $(p>0 \cdot 10$ for all lines)

\begin{tabular}{|c|c|c|c|c|}
\hline & $\begin{array}{l}\text { Progeny } \\
\text { tested }\end{array}$ & Resistant & Susceptible & $\chi^{2}(1 \mathrm{df})$ \\
\hline \multicolumn{5}{|c|}{ Susceptible parents } \\
\hline \multicolumn{5}{|c|}{ Family 3 : line } \\
\hline A & 39 & 0 & 39 & \\
\hline B & 48 & 0 & 48 & \\
\hline \multicolumn{5}{|c|}{ Family 4: line } \\
\hline A & 55 & 0 & 55 & \\
\hline B & 40 & 0 & 40 & \\
\hline \multicolumn{5}{|c|}{ Resistant parents } \\
\hline \multicolumn{5}{|c|}{ Family 3 : line } \\
\hline $\mathrm{C}$ & 31 & 31 & 0 & \\
\hline $\mathrm{D}$ & 36 & 36 & 0 & \\
\hline $\mathrm{E}$ & 46 & 46 & 0 & \\
\hline $\mathrm{F}$ & 42 & 42 & 0 & \\
\hline $\mathrm{G}$ & 39 & 26 & 13 & $1 \cdot 44$ \\
\hline $\mathrm{H}$ & 40 & 27 & 13 & $1 \cdot 20$ \\
\hline I & 22 & 16 & 6 & 0.06 \\
\hline$J$ & 26 & 21 & 5 & 0.46 \\
\hline \multicolumn{5}{|c|}{ Family 4: line } \\
\hline $\mathrm{C}$ & 43 & 43 & 0 & \\
\hline $\mathrm{D}$ & 44 & 44 & 0 & \\
\hline $\mathrm{E}$ & 33 & 23 & 10 & 0.49 \\
\hline $\mathrm{F}$ & 44 & 33 & 11 & 0 \\
\hline G & 36 & 27 & 9 & 0 \\
\hline $\mathrm{H}$ & 74 & 57 & 17 & $0 \cdot 16$ \\
\hline
\end{tabular}


This prediction was also confirmed (table 1). In $6 / 14$ lines examined, all plants were resistant. The remaining 8 lines included both resistant and susceptible plants. In none of these segregating lines was the ratio of resistant: susceptible plants significantly different from a $3: 1$ ratio (table 1$)$. There was no significant heterogeneity among lines $\left(\chi^{2}=\right.$ $3 \cdot 309,7 \mathrm{df}, p>0 \cdot 75)$, so data from these 8 lines were pooled. The overall ratio of resistant: susceptible plants was $230 R: 84 \mathrm{~S}$, which again is not significantly different from a $3: 1$ ratio $\left(\chi^{2}=0 \cdot 514\right.$, $1 \mathrm{df}, p>0 \cdot 25)$. Thus, all progeny tests of the plants in fig. 2 are consistent with the hypothesis that disease resistance within each family is controlled by a single locus, with resistance dominant. Although the disease reaction phenotypes and patterns of inheritance were identical for the two families, these data do not indicate whether the locus governing resistance is the same in the two families

The resistance phenotypes of heterozygotes and resistant homozygotes were so similar that individual plants could not be classified by genotype without progeny tests. However, analysis of sorus abortion frequency in segregating vs. nonsegregating progeny groups indicated that the allele for resistance was not completely dominant (table 2). The mean sorus abortion frequency in the resistant progeny of heterozygotes was significantly lower than that among progeny of resistant homozygotes. Resistant progeny of heterozygotes contain a mixture of heterozygotes and resistant homozygotes in an expected $2: 1$ ratio. Thus, these data indicate that the average sorus abortion frequency for heterozygotes alone is about 1-5 per cent below that of resistant homozygotes.

To examine the effect of this resistance factor on plant performance, resistant homozygotes and susceptible homozygotes derived from family 4 were inoculated with the pathogen isolate from Site B. Shoot biomass of inoculated seedlings, and of uninfected control seedlings, was measured after 31 days of growth (table 3). Among uninfected control plants, biomass did not differ significantly among the two genotype classes. For plants exposed to pathogens, resistant individuals had significantly greater biomass than susceptible plants. The resistance factor did not confer complete protection, since resistant plants inoculated with pathogens grew less than uninfected controls ( $t$-test, $p<0.01$ ). This may be due to the late stage at which resistance is expressed. Fungal sori on resistant plants died only after about 10 days of development, so resistant plants do experience
Table 2 Fungal sorus abortion frequency among resistant progeny of heterozygotes (A) and resistant homozygotes (B). Abortion frequency data were arcsine-transformed; after calculating means and 95 per cent confidence intervals, values were transformed back to the original frequency scale. Resistant progeny of heterozygotes should consist of $\frac{1}{3}$ homozygotes and $\frac{2}{3}$ heterozygotes, so the expec. ted phenotype of heterozygotes alone is estimated by $(A-$ $(1 / 3) B) /(2 / 3)$

\begin{tabular}{lll}
\hline Resistant progeny of: & Family 3 & Family 4 \\
\hline $\begin{array}{ll}\text { A. Heterozygotes } \\
\text { Mean \% sorus abortion }\end{array}$ & $93 \cdot 3 \%$ & \\
$95 \%$ C. I. & $91 \cdot 0-95 \cdot 2$ & $98 \cdot 7 \%$ \\
N & 85 & $87 \cdot 8-99 \cdot 3$ \\
B. Homozygotes & & \\
$\quad$ Mean \% sorus abortion & $96 \cdot 8 \%$ & $99 \cdot 6 \%$ \\
$95 \%$ C. I. & $95 \cdot 7-97 \cdot 7$ & $99 \cdot 3-99 \cdot 8$ \\
N & 103 & 71 \\
$t$ test & $t=3 \cdot 30$ & $t=2 \cdot 58$ \\
& $p<0 \cdot 01$ & $p<0 \cdot 02$ \\
Expected heterozygote & & \\
phenotype & $91 \cdot 5 \%$ & $98 \cdot 2 \%$ \\
\hline
\end{tabular}

some immediate damage even though pathogen reproduction is terminated. Nevertheless, resistant seedlings exposed to pathogens still had a 32 per cent higher growth rate than infected susceptible plants. In natural environments, large plant size early in life was associated with a higher probability of survivorship to reproductive age (Parker, 1986). Thus, this resistance factor is likely to be favoured by selection in areas where pathogens similar to the Site B isolate are prevalent.

\section{DISCUSSION}

The finding of a single dominant gene for disease resistance in $A$. bracteata conforms to the typical pattern of inheritance of resistance in crop plants, where dominant genes with large phenotypic effects play a primary role in controlling disease resistance (Day, 1974). Day et al. (1983) and Barrett (1985) have questioned whether this pattern of disease resistance inheritance in crops necessarily represents a fundamental feature of

Table 3 Shoot dry mass $(\mathrm{mg})$ of resistant and suceptible homozygotes from family 4 grown without exposure to pathogens, or inoculated with the Site $B$ pathogen isolate

\begin{tabular}{lccl}
\hline & Resistant & Susceptible & $t$ test \\
\hline Uninfected plants & & & \\
$\quad$ mean \pm 1 SE & $213 \pm 24$ & $198 \pm 13$ & $p>0.50$ \\
$N$ & 10 & 10 & \\
Infected plants & & & \\
$\quad$ mean \pm 1 SE & $157 \pm 8$ & $119 \pm 12$ & $p<0.01$ \\
$N$ & 39 & 40 & \\
\hline
\end{tabular}


plant-pathogen interactions, because it may result in part from plant breeding procedures. Due to the greater difficulty of working with recessive resistance factors, or with any form of resistance with complex inheritance, many plant breeding programs consciously or unconsciously focus on dominant genes that have dramatic effects on a plant's resistance phenotype. By contrast, a range of different genetic mechanisms for resistance may be important in natural plant populations, including both major gene resistance and polygenic variation (Segal et al., 1980; Burdon, 1982; Day et al., 1983). These results for $A$. bracteata document the existence of one major gene resistance mechanism, but do not rule out the possibility that other resistance traits in this species may have a different genetic basis. In controlled environment studies (Parker, 1986), significant variation was observed among $A$. bracteata families both for infection intensity (mean number of sori initiated per plant) and for disease tolerance (plant growth rate at constant infection intensity). The genetic basis of these traits has not been investigated, but polygenic control cannot be ruled out at present, since both traits exhibited wide, continuous variation.

The evolutionary interaction between $A$. bracteata and its pathogen will be strongly affected by the degree of specificity of genes conferring resistance. The two plant families resistant to the Site $B$ and $C$ pathogen strains were completely susceptible to the two pathogen strains from Site A (fig. 1). Subsequent inoculation studies have confirmed that the resistance factor possessed by these plants has only narrow effectiveness: resistant homozygotes from both families proved to be entirely susceptible to a pathogen isolate from Site A (personal observations). Thus, the selective value of this resistance factor will vary depending on the genetic composition of the pathogen population. Pathogen genotypes capable of attacking plants with this resistance factor already exist in this habitat, so it is likely to be selectively favoured only when rare. Should this resistance factor become common in the plant population, it will simply result in natural selection on pathogens in favour of those genotypes capable of attacking plants with this factor. Thus, any increase in frequency of this resistance factor due to its ability to protect plants from disease may trigger rapid counteradaptation by pathogens. Studies in progress are estimating the frequency of this resistance factor in the $A$. bracteata population, and are examining whether any plants possess resistance to the other pathogen genotypes present in this area.
Acknowledgments I am grateful to A. Salzman for generous assistance in the field and laboratory. Financial support was provided by the State University of New York at Binghamton.

\section{REFERENCES}

ALEXANDER, H. M., ANTONOVICS, J. AND RAUSHER, M. D. 1984. Relationship of phenotypic and genetic variation in Plantago lanceolata to disease caused by Fusarium moniliforme var. subglutinans. Oecologia, 62, 89-93.

BARRETT, J. A. 1985. The gene-for-gene hypothesis: parable or paradigm. In Rollinson, D. and Anderson, R. M. (eds.) Ecology and Genetics of Host-Parasite Interactions, Academic Press, pp. 215-225.

BURDON, J. J. 1980. Variation in disease-resistance within a population of Trifolium repens. Journal of Ecology, 68, 737-744.

BURDON, J. J. 1982. The effect of fungal pathogens on plant communities. In Newman, E. I. (ed.) The Plant Community as a Working Mechanism, Blackwell, pp. 99-112.

BURDON, J. J. AND MARSHALL, D. R. 1981. Inter- and intraspecific diversity in the disease-response of Glycine species to the leaf-rust fungus Phakopsora pachyrhizi. Journal of Ecology, 69, 381-390.

BURDON, J. J., OATES, J. D. AND MARSHALL, D. R. 1983. Interactions between Avena and Puccinia species. I. The wild hosts: Avena barbata, A. fatua, A. ludoviciana. Journal of Applied Ecology, 20, 571-584.

DAY, P. R. 1974. Genetics of Host-Parasite Interaction. W. H. Freeman.

DAY, P. R., BARRETT, J. A. AND wOLFE, M. S. 1983. The evolution of host-parasite interaction. In Kosuge, T., Meredith, C. P. and Hollaender, A. (eds.) Genetic Engineering of Plants: an Agricultural Perspective, Plenum Press, pp. 419430.

DINOOR, A. AND ESHED, N. 1984. The role and importance of pathogens in natural plant communities. Ann. Rev. Phytopathol., 22, 443-466.

HARRY, I. B. AND CLARKE, D. D. 1986. Race-specific resistance in groundsel (Senecio vulgaris) to the powdery mildew Erysiphe fischeri. New Phytol., 103, 167-175.

KARLING, J. S. 1964. Synchytrium. Academic Press.

PARKER, M. A. 1985. Local population differentiation for compatibility in an annual legume and its host-specific fungal pathogen. Evolution, 39, 713-723.

PARKER, M. A. 1986. Individual variation in pathogen attack and differential reproductive success in the annual legume, Amphicarpaea bracteata. Oecologia, 69, 253-259.

SCHNEE, B. K. AND WALlER, D. M. 1986. Reproductive behavior of Amphicarpaea bracteata (Leguminosae), an amphicarpic annual. Amer. J. Botany, 73, 376-386.

SEGAL, A., MANISTERSKI, J., FISCHBECK, G. AND WAHL, I. 1980. How plant populations defend themselves in natural ecosystems. In Horsfall, J. G. and Cowling, E. B. (eds.) Plant Disease: An Advanced Treatise, vol. 5, Academic Press, pp. 75-102.

WAHL, I. 1970. Prevalence and geographic distribution of resistance to crown rust in Avena sterilis. Phytopathology, 60, 746-749.

ZIMMER, D. E. AND REHDER, D. 1976. Rust resistance of wild Helianthus species of the north central United States. Phytopathology, 66, 208-211 